\title{
Sleep patterns and the risk for ADHD: a review
}

\author{
This article was published in the following Dove Press journal: \\ Nature and Science of Sleep \\ 27 May 2012 \\ Number of times this article has been viewed
}

\author{
Jamie Cassoff ${ }^{1,2}$ \\ Sabrina T Wiebe ${ }^{1,2}$ \\ Reut Gruber ${ }^{1,2}$ \\ 'Attention, Behavior and Sleep Lab, \\ Douglas Mental Health University \\ Institute, Montréal, Quebec, Canada; \\ ${ }^{2}$ McGill University, Montréal, Quebec, \\ Canada
}

\begin{abstract}
Attention-deficit/hyperactivity disorder (ADHD) is often associated with comorbid sleep disturbances. Sleep disturbances may be a risk factor for development of the disorder, a symptom of the disorder, or a comorbid condition affected by a similar psychopathology. Various studies have examined the impact of sleep deprivation on the presence/exacerbation of ADHD symptomology, as well as longitudinal and concurrent associations between different sleep disturbances and ADHD, yet the notion of sleep disturbances as a predecessor to ADHD remains unclear. As such, this review examines the evidence for sleep disturbances as a risk factor for the development of ADHD, as well as the mechanisms underlying the association between sleep patterns and ADHD. Additionally, clinical implications regarding the comorbid nature of sleep disturbances and ADHD will be considered.
\end{abstract}

Keywords: sleep disturbances, ADHD, development

\section{Introduction}

Attention-deficit/hyperactivity disorder (ADHD) is one of the most commonly diagnosed childhood disorders, affecting approximately $3 \%-5 \%$ of school-aged children ${ }^{1}$ and enduring throughout adolescence and adulthood. A diagnosis of ADHD is dependent on developmentally inappropriate symptoms of inattention, hyperactivity, and/or impulsivity, with onset before the age of 7 years, and impaired functioning in two or more settings. ${ }^{2}$ Sleep difficulties are often comorbid with ADHD. ${ }^{3}$ In fact, $25 \%-50 \%$ of children and adolescents with ADHD also report sleep disturbances. ${ }^{4}$ Despite the high comorbidity between sleep disturbances and psychopathology, it is unclear if sleep disturbance is a cause, a consequence, or a comorbid problem that is associated with such disturbances. Previous research has examined the complexity of the relationship between sleep disturbances and ADHD and a bidirectional association has been suggested, ${ }^{5}$ such that sleep contributes to increased manifestation of ADHD symptoms (eg, inattention, hyperactivity, impulsivity) and ADHD contributes to worsened sleep. ${ }^{6}$ To what extent sleep problems are a risk for development of ADHD versus the outcome of the psychological condition is unclear, however. Thus, this review will examine (1) evidence for various sleep aspects as risk factors for both exacerbation and development of ADHD; (2) mechanisms underlying the relationship between sleep disturbances and ADHD; and (3) clinical implications of the interplay between sleep and ADHD.

(respondence: Reut Gruber Department of Psychiatry, McGill University, Douglas Mental Health University Institute, 6875 LaSalle Blvd, Verdun, Quebec H4H IR3, Canada

Tel $+5|476| 6|3|$ ext 3476

Fax +5I4762 3858

Email reut.gruber@douglas.mcgill.ca

\section{Methods}

A literature search was performed using PubMed, Google Scholar, and PsycINFO. The following keywords were used in various combinations: sleep, psychopathology, 
ADHD, attention deficit hyperactivity disorder, risk factor, predictor, development, sleep restriction, sleep deprivation, sleep patterns, insomnia, and sleep problems. Reference sections of appropriate articles were also used to obtain other relevant articles. Articles that directly assessed the variables of interest (sleep and ADHD) were kept and precedence was given to studies showing a directional relationship between sleep and ADHD. Nine articles concerning the longitudinal association between sleep disturbances and ADHD, three articles pertaining to experimental sleep deprivation and ADHD, nine correlational studies utilizing regression to assess sleep disturbances as a risk for ADHD, and three treatment outcome studies involving sleep disorder treatment and ADHD outcomes, were reviewed.

Although definitions of sleep terminology are inconsistent amongst various studies, in this review, sleep deprivation refers to total sleep deprivation, that is, the purposeful elimination of sleep during at least a 24 hour period $^{7}$ and/or partial sleep deprivation (also known as sleep restriction), that is, the purposeful elimination of sleep from one's needed amount for optimal performance; and sleep disturbances refers to diagnosable sleep disorders, such as sleep onset insomnia, parasomnias and other sleep disorders, as well as dysfunctions of sleep architecture and continuity. ${ }^{8}$

\section{Sleep deprivation as a risk factor for ADHD symptoms}

Although some studies fail to find an association between sleep restriction and ADHD symptomology, ${ }^{9}$ the majority of studies with typically developing children and children with ADHD have demonstrated that sleep deprivation can result in deficits in neurobehavioral functioning that resembles or exacerbates ADHD symptoms (see Table 1 for a summary of studies). For example, Sadeh et $\mathrm{al}^{10}$ and Gruber et $\mathrm{al}^{11}$ assessed the effect of cumulative sleep deprivation on neurobehavioral functioning of both typically developing children ${ }^{11,12}$ and children with ADHD. ${ }^{12}$ In both studies, it was found that sleep deprivation resulted in a significant decrease in performance on the continuous performance task, a neurobehavioral task requiring sustained attention and behavioral inhibition that is commonly used in the evaluation of inattention and impulsivity in children with ADHD. Furthermore, in the study by Gruber et $\mathrm{al}^{12}$ performance of the ADHD group deteriorated from subclinical levels of inattention to clinical levels of inattention following sleep deprivation, emphasizing the negative impact on ADHD symptomology.

Further support for the impact of sleep deprivation on inattention has been exhibited through findings in studies utilizing teacher reports of ADHD symptoms. For instance, using an experimental sleep restriction paradigm, Fallone and colleagues ${ }^{12}$ found that following sleep restriction, observers reported increased attention difficulties. ${ }^{12}$ Gruber and colleagues ${ }^{13}$ have also recently shown that teachers of typically developing school-aged children, who were blind to their students' sleep status, reported increased cognitive problems and inattention after sleep restriction confirmed by polysomnography. In another longitudinal study by Touchette and colleagues, ${ }^{14}$ sleep duration at ages 2.5, 3.5, 4,5 , and 6 years old predicted parent reported hyperactivityimpulsivity at age 6. Additionally, the risk for hyperactivityimpulsivity was 3.2 times greater for children who had shorter sleep duration at 41 months old as compared to those receiving adequate sleep.

Collectively, these findings suggest that cumulative sleep deprivation is associated with increased ADHD symptoms of inattention. However, sleep deprivation is not the only problem encountered by children with ADHD and it is important to understand the impact that sleep disturbances may have on ADHD symptomology.

\section{Sleep disturbances as a risk factor for ADHD}

Sleep disturbances, such as fragmented sleep, bedtime resistance, and sleep onset insomnia in early childhood, have been found to be associated with increased likelihood of developing ADHD symptoms later on. For instance, Gregory and $\mathrm{O}^{\prime} \mathrm{Connor}^{15}$ examined the concurrent and predictive associations between sleep and behavioral problems in children over an 11-year period and found that sleep disturbances at age 4 predicted attention and aggression problems at age 15 . Another study ${ }^{16}$ revealed similar associations, with sleep problems between the ages of 2-4 predicting attention deficits at age 5 . These studies suggest that sleep disturbances in early childhood may be an initial symptom of later ADHD, or may be a causal factor in the development of future ADHD symptoms.

Not just the presence of sleep disturbance, but also the stability of sleep disturbance over time appears to be important in determining to what extent it is a risk factor for behavioral disorders such as ADHD. Friedman and colleagues ${ }^{17}$ conducted a longitudinal study following children from the age of 4, 5, 7, and 9-16 years old. Results revealed that individuals whose sleep disturbances (ie, bedwetting) decreased over time showed better executive control in adolescence than those whose sleep disturbances remained relatively stable. These findings suggest that the presence of 


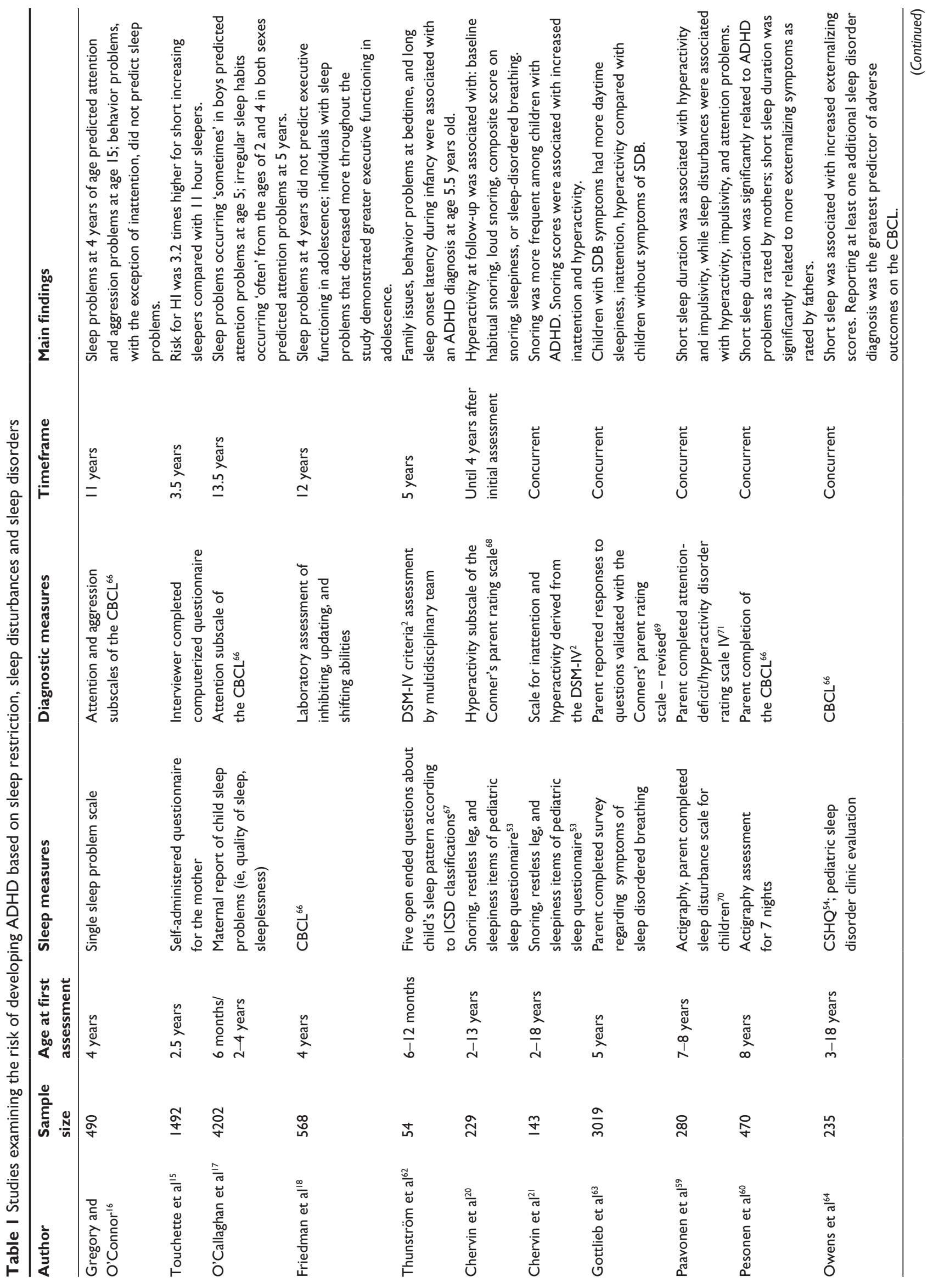


stable sleep disturbances over childhood is a significant risk factor for the development of subsequent ADHD.

It is not unusual for a diagnosis of ADHD to be accompanied by comorbid primary sleep disorders, such as sleep-disordered breathing (SDB) and restless legs syndrome (RLS). Various studies have examined the association between these disorders and ADHD symptomology and have found that primary sleep disorders can exacerbate ADHD symptoms.

\section{SDB}

SDB, including frequent snoring and obstructive sleep apnea, has been associated with increased levels of hyperactivity and inattention. ${ }^{18}$ For example, Chervin and colleagues ${ }^{19}$ found that children demonstrating elevated scores on the snoring index of a SDB measure were at increased risk for developing hyperactivity symptoms 4 years later. In another study, ${ }^{20}$ it was found that untreated SDB was related to a higher likelihood of being diagnosed with ADHD. Furthermore, research examining children with comorbid obstructive sleep apnea and $\mathrm{ADHD}^{21,22}$ has demonstrated that treatment of the sleep disorder by adenotonsillectomy surgery results in significant improvements in attention and reduced hyperactivity.

\section{RLS}

There is evidence of a positive association between a diagnosis of RLS and severity of ADHD symptoms. For example, Konofal and colleagues ${ }^{23}$ investigated the impact of RLS on ADHD severity in 5-8 year old children and found that ADHD symptoms were more severe in children with both ADHD and RLS than ADHD alone. It was proposed that the sleep fragmentation involved with RLS might exacerbate symptoms of attention and hyperactivity associated with ADHD. Taken together, these findings support the notion that sleep problems can play a substantial role in contributing to ADHD symptoms and suggest an important link between sleep pathophysiology and the pathophysiology of ADHD.

\section{Developmental considerations}

It was originally believed that ADHD symptoms tended to wane in adolescence. This may account for the fact that, in comparison to the abundance of research on ADHD in pediatric populations, the research on ADHD in adult populations is quite sparse. However, it is known that ADHD is a lifelong disorder affecting individuals from childhood to adulthood. Studies ${ }^{24-28}$ show that, similar to the sleep complaints demonstrated by children and adolescents with ADHD, sleep problems are also common in adults with the disorder, as evidenced by high rates of self-reported sleep problems in up 
to $83 \%$ of adults assessed for ADHD. Data on sleep efficiency in adults with ADHD are inconsistent, with one PSG study depicting no differences as compared with normal controls, ${ }^{28}$ whereas another found reduced sleep efficiency, an elevated number of awakenings, a higher percentage of wakefulness after sleep onset, and a reduction in the percentage of rapid eye movement (REM) sleep in individuals with the disorder. ${ }^{29}$ In summary, the sleep disturbances characteristics of adults with ADHD seem to resemble those found in children including reduced REM sleep and nocturnal awakenings. This suggests the notion that rather than waning in adolescence, sleep disturbances in individuals with ADHD persist throughout the lifespan.

\section{Common underlying pathophysiology between sleep problems and ADHD}

Several common underlying mechanisms have been suggested to account for the link between sleep disturbances and symptoms of ADHD. In particular, prefrontal cortex (PFC) functions, dopamine, and the circadian system have been suggested as potential links between the sleep-wake system and ADHD.

\section{PFC}

The PFC is implicated in the regulation of sleep and wakefulness, as well as in carrying out executive functions. ${ }^{30}$ Executive functions consist of behavioral inhibition, attentional tasks, setshifting, working memory, analysis/synthesis, and contextual memory, ${ }^{31}$ functions which are impaired in individuals with ADHD. Various sleep deprivation ${ }^{32,33}$ studies have found that the functions most affected are those controlled by the PFC namely, the executive functions. This process has been found to occur through the disruption of cellular homeostasis in the PFC. ${ }^{31}$ As such, underlying deficits in the PFC as a result of sleep disruption can lead to executive functioning deficits characteristic of individuals with ADHD.

\section{Dopaminergic system}

Dopaminergic activity, particularly in the PFC, is associated with ADHD symptomology ${ }^{34}$ and is also implicated in the regulation of sleep and waking. ${ }^{35}$ Dopamine has been found to be important in modulating performance on tasks of executive functions, ${ }^{36}$ such as attention, which are the areas of greatest impairment in individuals with ADHD. ${ }^{37,38}$ As well, dopamine levels in the substantia nigra and the ventral tegmental area have been shown to be involved in promoting wakefulness. ${ }^{39}$ For example, injection of dopamine agonists into rat brains results in more wakefulness and wake-like behaviors, ${ }^{40}$ showing that higher dopaminergic activity is involved in maintaining wakefulness. Other evidence comes from studies which show that dopamine levels tend to be decreased following sleep restriction and are associated with impaired waking functions. ${ }^{41}$

Further evidence for dopamine's role in ADHD and the sleep-wake cycle comes from genetic studies examining catechol-O-methyltransferase (COMT), a gene that encodes for a dopamine-degrading enzyme. It has been suggested that COMT activity contributes to sleep problems in individuals with ADHD because of its role in the metabolism of dopamine. ${ }^{42}$ The high activity variant of the COMT gene, the valine (Val) allele, results in decreased concentrations of dopamine compared to that of the low activity variant, methionine (Met). When sleep was compared in children with ADHD having the Val-Val or Val-Met polymorphisms to those with the low activity Met-Met polymorphism, it was revealed that children with decreased cortical dopamine had poorer sleep continuity than their counterparts. ${ }^{43}$ Such research suggests a role of dopamine in the underlying genetic pathophysiology of ADHD and sleep disturbances.

\section{Circadian system}

A maladjusted circadian rhythm may also be implicated in the potential pathophysiological association between sleep disturbances and ADHD. ${ }^{44}$ Indeed, delayed circadian rhythms, as evidenced by a delayed nighttime increase in endogenous melatonin, have been demonstrated in nonmedicated children with ADHD. ${ }^{45}$ Such a delay in their endogenous circadian system may disrupt the timing of their sleep and wake periods and account for other sleep disturbances. Additionally, deficits in the circadian system may result in increased daytime fatigue and in bedtime refusal, ${ }^{45}$ potentially mimicking ADHD-like symptoms. In this way, the circadian system may offer another potential pathophysiological explanation for the link between sleep disturbances and ADHD.

\section{Clinical implications}

Given that sleep disorders, such as obstructive sleep apnea and RLS, as well as the presence of chronic sleep disturbances and/or sleep deprivation, can result in behaviors that mimic or exacerbate ADHD-symptomology $y^{12,46-49}$ (eg, hyperactivity and inattention), screening for such conditions is an essential component in the assessment of children with symptoms of inattention or hyperactivity. ${ }^{50}$ Sleep assessments during the ADHD diagnostic process are feasible in primary care settings through brief screening tools (eg, BEARS ${ }^{51}$ 
[B = bedtime issues, $\mathrm{E}=$ excessive daytime sleepiness, $\mathrm{A}=$ night awakenings, $\mathrm{R}=$ regularity and duration of sleep, $\mathrm{S}=$ snoring]) and parent report surveys (eg, Pediatric Sleep Questionnaire, ${ }^{52}$ Child Sleep Habit Questionnaire ${ }^{53}$ ). A review of sleep problems should occur during the baseline assessment (ie, when diagnosing ADHD), as well as on an ongoing basis during the management of the disorder. ${ }^{51}$ Polysomnography should be considered to confirm sleep disorder diagnoses for individuals whose reported symptoms are suggestive of breathing problems or nocturnal leg movements. ${ }^{54}$ As well, sleep diaries and actigraphy ${ }^{55}$ are useful tools for evaluating quantity and quality of sleep, as well as assessing variability of sleep patterns in children with ADHD. When sleep problems or disorders are encountered, it is important to treat both the symptoms of ADHD, as well as the sleep problems themselves, as the presence of such sleep problems will likely decrease the efficacy of an intervention aimed solely at improving ADHD symptoms.

Finally, the presence of sleep problems should be considered when prescribing stimulant medications, as these can produce symptoms of insomnia or worsen already existing problems. ${ }^{56,57}$ As such, individuals with ADHD should be monitored for development of sleep problems following medication administration, as well as having their medications titrated to optimum doses for improving ADHD symptoms, while limiting potential negative effects on sleep.

\section{Methodological considerations}

The interpretation of findings obtained in studies regarding sleep and ADHD is challenging given the inconsistent definitions of sleep problems and the measures used to record sleep. The reviewed studies are at times inconsistent with regards to their definition of sleep restriction, disorders, and disturbance and, thus, utilize varying diagnostic criteria when examining sleep problems associated with ADHD. For example, objective (eg, apnea hypopnea inde ${ }^{23}$ ) and subjective (eg, Pediatric Sleep Questionnaire ${ }^{20}$ ) are being used to define sleep disordered breathing. In addition, sleep recording methods, as well as the types and number of sleep parameters measured using these methods, vary between studies. Different studies use different objective actigraphy ${ }^{58,59}$ and polysomnography ${ }^{14,61}$ or subjective parental report ${ }^{15-18,20,21,60-64}$ measures, and, as a result, it is difficult to compare findings between studies. It is, therefore, crucial for future studies to make an attempt to utilize consistent, sleep related terminology and diagnostic criteria when examining the relationship between sleep and ADHD.

\section{Summary and future directions}

Sleep deprivation and sleep disturbances are prevalent in children with ADHD and have been shown to exacerbate ADHD symptomology, including inattention, hyperactivity, and impulsivity. Additionally, restoration of proper sleep patterns in children with ADHD has been found to alleviate symptomology, whereas experimental sleep restriction has been shown to worsen such symptoms, suggesting that sleep problems can contribute to the manifestation of ADHD symptoms. Furthermore, longitudinal research suggests that sleep disturbances in early childhood are a risk factor for the subsequent development of ADHD later on in childhood and adolescence. As such, although the relationship between sleep disturbances and ADHD appears to be bidirectional, there is support for the role of sleep disturbances as a predecessor to the disorder. It is, thus, important for healthcare providers to integrate sleep components into ADHD diagnostic and treatment plans. Future research should investigate the relationship between ADHD etiology (eg, ADHD and comorbid psychopathologies, ADHD and comorbid sleep disorders, and ADHD without comorbid sleep disorders) and sleep disturbances, as well as clarify the effects of sleep deprivation on specific ADHD symptomology. Additional longitudinal research is needed to further understand the potential causal relationship between sleep patterns and ADHD.

The association between disrupted sleep patterns and ADHD appears to be modulated by the PFC and the dopaminergic system. Further elucidation of the ways in which these systems relate to both sleep and the presence of psychological disorders can help improve interventions by targeting both the disorder and the sleep disturbances involved.

\section{Disclosure}

The authors report no conflicts of interest in this work.

\section{References}

1. Polanczyk G, De Lima MS, Horta BL, Biederman J, Rohde LA. The worldwide prevalence of ADHD: a systematic review and metaregression analysis. Am J Psychiatry. 2007;164(6):942-948.

2. American Psychiatric Association. Diagnostic and Statistical Manual of Mental Disorders. 4th ed, text revision. Washington, DC: American Psychiatric Association; 2000.

3. Krahn LE. Psychiatric disorders associated with disturbed sleep. Semin Neurol. 2005;25(1):90-96.

4. Corkum P, Tannock R, Moldofsky H. Sleep disturbances in children with attention-deficit/hyperactivity disorder. J Am Acad Child Adolesc Psychiatry. 1998;37(6):637-646.

5. Owens JA. The ADHD and sleep conundrum: a review. J Dev Behav Pediatr. 2005;26(4):312-322.

6. Alfano CA, Gamble AL. The role of sleep in childhood psychiatric disorders. Child Youth Care Forum. 2009;38(6):327-340.

7. Reynolds AC, Banks S. Total sleep deprivation, chronic sleep restriction and sleep disruption. Prog Brain Res. 2010;185:91-103. 
8. Cormier RE. Sleep disturbances. In: Walker HK, Hall WD, Hurst JW, editors. Clinical methods: The History, Physical, and Laboratory Examinations. 3rd ed. Boston: Butterworths; 1990.

9. Fallone G, Acebo C, Arnedt JT, Seifer R, Carskadon MA. Effects of acute sleep restriction on behavior, sustained attention, and response inhibition in children. Percept Mot Skills. 2001;93(1):213-229.

10. Sadeh A, Gruber R, Raviv A. The effects of sleep restriction and extension on school-age children: what a difference an hour makes. Child Dev. 2003;74(2):444-455.

11. Gruber R, Wiebe S, Montecalvo L, Brunetti B, Amsel R, Carrier J. Impact of sleep restriction on neurobehavioral functioning of children with attention deficit hyperactivity disorder. Sleep. 2011;34(3): 315-323.

12. Fallone G, Acebo C, Seifer R, Carskadon MA. Experimental restriction of sleep opportunity in children: effects on teacher ratings. Sleep. 2005;28(12):1561.

13. Gruber R, Michaelsen S, Bergmame L, et al. Short sleep duration is associated with teacher-reported inattention and cognitive problems in healthy school-aged children. Nat Sci Sleep. 2012;4:33-40.

14. Touchette É, Petit D, Séguin JR, Boivin M, Tremblay RE, Montplaisir JY. Associations between sleep duration patterns and behavioral/cognitive functioning at school entry. Sleep. 2007;30(9):1213-1219.

15. Gregory AM, O'Connor TG. Sleep problems in childhood: a longitudinal study of developmental change and association with behavioral problems. J Am Acad Child Adolesc Psychiatry. 2002;41(8):964-971.

16. O'Callaghan FV, Al Mamun A, O'Callaghan M, et al. The link between sleep problems in infancy and early childhood and attention problems at 5 and 14 years: Evidence from a birth cohort study. Early Hum Dev. 2010;86(7):419-424.

17. Friedman NP, Corley RP, Hewitt JK, Wright Jr KP. Individual differences in childhood sleep problems predict later cognitive executive control. Sleep. 2009;32(3):323-333.

18. Chervin RD, Archbold KH, Dillon JE, et al. Inattention, hyperactivity, and symptoms of sleep-disordered breathing. Pediatrics. 2002; 109(3):449.

19. Chervin RD, Ruzicka DL, Archbold KH, Dillon JE. Snoring predicts hyperactivity four years later. Sleep. 2005;28(7):885-890.

20. Chervin RD, Bassetti C, Ganoczy DA, Pituch KJ. Pediatrics and sleep symptoms of sleep disorders, inattention, and hyperactivity in children. Sleep. 1997;20(12):1185-1192.

21. Fidan T, Fidan V. The impact of adenotonsillectomy on attentiondeficit hyperactivity and disruptive behavioral symptoms. The Eurasian Journal of Medicine. 2008;40(1):14-17.

22. Huang YS, Guilleminault C, Li HY, Yang CM, Wu YY, Chen NH Attention-deficit/hyperactivity disorder with obstructive sleep apnea: a treatment outcome study. Sleep Med. 2007;8(1):18-30.

23. Konofal E, Cortese S, Marchand M, Mouren MC, Arnulf I, Lecendreux M. Impact of restless legs syndrome and iron deficiency on attention-deficit/hyperactivity disorder in children. Sleep Med. 2007;8(7):711-715.

24. Dodson W, Zhang Y. Sleep Disturbances Associated with Adult ADHD. Presented at: New research program and abstracts, 152nd annual meeting of the American Psychiatric Association; May 15-20, 1999; Washington, DC.

25. Kooij J, Middelkoop HA, van Gils K, Buitelaar JK. The effect of stimulants on nocturnal motor activity and sleep quality in adults with ADHD: an open-label case-control study. J Clin Psychiatry. 2001;62(12):952-956.

26. Schredl M, Alm B, Sobanski E. Sleep quality in adult patients with attention deficit hyperactivity disorder (ADHD). Eur Arch Psychiatry Clin Neurosci. 2007;257(3):164-168.

27. Philipsen A, Feige B, Hesslinger B, et al. Sleep in adults with attention-deficit/hyperactivity disorder: a controlled polysomnographic study including spectral analysis of the sleep EEG. Sleep. 2005;28(7): 877-884.

28. Philipsen A, Hornyak M, Riemann D. Sleep and sleep disorders in adults with attention deficit/hyperactivity disorder. Sleep Med Rev. 2006;10(6):399-405
29. Sobanski E, Schredl M, Kettler N, Alm B. Sleep in adults with attention deficit hyperactivity disorder (ADHD) before and during treatment with methylphenidate: a controlled polysomnographic study. Sleep. 2008;31(3):375-381.

30. Walters AS, Silvestri R, Zucconi M, Chandrashekariah R, Konofal E. Review of the possible relationship and hypothetical links between attention deficit hyperactivity disorder (ADHD) and the simple sleep related movement disorders, parasomnias, hypersomnias, and circadian rhythm disorders. J Clin Sleep Med. 2008;4(6):591-600.

31. Beebe DW, Gozal D. Obstructive sleep apnea and the prefrontal cortex: towards a comprehensive model linking nocturnal upper airway obstruction to daytime cognitive and behavioral deficits. J Sleep Res. 2002;11(1):1-16.

32. Herscovitch J, Stuss D, Broughton R. Changes in cognitive processing following short-term cumulative partial sleep deprivation and recovery oversleeping. J Clin Neuropsychol. 1980;2(4):301-319.

33. Randazzo AC, Muehlbach MJ, Schweitzer PK, Walsh JK. Cognitive function following acute sleep restriction in children ages 10-14. Sleep. 1998;21(8):861-868.

34. Solanto MV. Dopamine dysfunction in AD/HD: integrating clinical and basic neuroscience research. Behav Brain Res. 2002;130(1-2): $65-71$.

35. Monti JM, Monti D. The involvement of dopamine in the modulation of sleep and waking. Sleep Med Rev. 2007;11(2):113-133.

36. Robbins T, Roberts A. Differential regulation of fronto-executive function by the monoamines and acetylcholine. Cereb Cortex. 2007;17 Suppl 1:i151-i160.

37. Willcutt EG, Doyle AE, Nigg JT, Faraone SV, Pennington BF. Validity of the executive function theory of attention-deficit/hyperactivity disorder: a meta-analytic review. Biol Psychiatry. 2005;57(11): 1336-1346.

38. Barkley RA. Behavioral inhibition, sustained attention, and executive functions: Constructing a unifying theory of ADHD. Psychol Bull. 1997;121(1):65-94.

39. Korotkova TM, Sergeeva OA, Eriksson KS, Haas HL, Brown RE. Excitation of ventral tegmental area dopaminergic and nondopaminergic neurons by orexins/hypocretins. J Neurosci. 2003;23(1):7-11.

40. Isaac SO, Berridge CW. Wake-promoting actions of dopamine D1 and D2 receptor stimulation. $J$ Pharmacol Exp Ther. 2003;307(1): 386-394.

41. Lal S, Thavundayil J, Nair N, et al. Effect of sleep deprivation on dopamine receptor function in normal subjects. $J$ Neural Transm. 1981;50(1):39-45.

42. Frauscher B, Högl B, Maret S, et al. Association of daytime sleepiness with COMT polymorphism in patients with parkinson disease: a pilot study. Sleep. 2004;27(4):733-736.

43. Gruber R, Grizenko N, Schwartz G, et al. Sleep and COMT polymorphism in ADHD children: preliminary actigraphic data. $J \mathrm{Am}$ Acad Child Adolesc Psychiatry. 2006;45(8):982-989.

44. Gruber R. Sleep characteristics of children and adolescents with attention deficit-hyperactivity disorder. Child Adolesc Psychiatr Clin NAm. Oct 2009;18(4):863-876.

45. Van der Heijden KB, Smits MG, Someren EJWV, Boudewijn Gunning W. Idiopathic chronic sleep onset insomnia in attention-deficit/hyperactivity disorder: a circadian rhythm sleep disorder. Chronobiol Int. 2005;22(3):559-570.

46. Rowland AS, Lesesne CA, Abramowitz AJ. The epidemiology of attention-deficit/hyperactivity disorder (ADHD): A public health view. Ment Retard Dev Disabil Res Rev. 2002;8(3):162-170.

47. Chronis AM, Lahey BB, Pelham Jr WE, Kipp HL, Baumann BL, Lee SS Psychopathology and substance abuse in parents of young children with attention-deficit/hyperactivity disorder. J Am Acad Child Adolesc Psychiatry. 2003;42(12):1424-1432.

48. Konofal E, Lecendreux M, Cortese S. Sleep and ADHD. Sleep Med. 2010;11(7):652-658.

49. Gozal D, Kheirandish-Gozal L. Neurocognitive and behavioral morbidity in children with sleep disorders. Curr Opin Pulm Med. 2007;13(6):505-509. 
50. Subcommittee on Attention-Deficit/Hyperactivity Disorder, Steering Committee on Quality Improvement and Management, Wolraich M, et al. ADHD: Clinical practice guideline for the diagnosis, evaluation, and treatment of attention-deficit/hyperactivity disorder in children and adolescents. Pediatrics. 2011;128(5):1007-1022.

51. Owens JA, Dalzell V. Use of the 'BEARS' sleep screening tool in a pediatric residents' continuity clinic: a pilot study. Sleep Med. 2005;6(1):63-69.

52. Chervin RD, Hedger K, Dillon JE, Pituch KJ. Pediatric sleep questionnaire (PSQ): validity and reliability of scales for sleep-disordered breathing, snoring, sleepiness, and behavioral problems. Sleep Med. 2000;1(1):21-32.

53. Owens JA, Spirito A, McGuinn M. The Children's Sleep Habits Questionnaire (CSHQ): Psychometric properties of a survey instrument for school-aged children. Sleep. 2000;23(8):1043-1051.

54. Sadeh A, Pergamin L, Bar-Haim Y. Sleep in children with attentiondeficit hyperactivity disorder: a meta-analysis of polysomnographic studies. Sleep Med Rev. 2006;10(6):381-398.

55. Owens J, Sangal RB, Sutton VK, Bakken R, Allen AJ, Kelsey D. Subjective and objective measures of sleep in children with attentiondeficit/hyperactivity disorder. Sleep Med. 2009;10(4):446-456.

56. Stein MA, Sarampote CS, Waldman ID, et al. A dose-response study of OROS methylphenidate in children with attention-deficit/hyperactivity disorder. Pediatrics. 2003;112(5):e404.

57. O'Brien LM, Ivanenko A, Crabtree VML, et al. The effect of stimulants on sleep characteristics in children with attention deficit/hyperactivity disorder. Sleep Med. 2003;4(4):309-316.

58. Paavonen EJ, Räikkönen K, Lahti J, et al. Short sleep duration and behavioral symptoms of attention-deficit/hyperactivity disorder in healthy 7- to 8-year-old children. Pediatrics. 2009;123(5): e857-e864.

59. Pesonen AK, Räikkönen K, Paavonen EJ, et al. Sleep duration and regularity are associated with behavioral problems in 8-year-old children. Int J Behav Med. 2010;17(4):298-305.

60. O'Brien LM, Holbrook CR, Mervis CB, et al. Sleep and neurobehavioral characteristics of 5- to 7-year-old children with parentally reported symptoms of attention-deficit/hyperactivity disorder. Pediatrics. 2003;111(3):554-563.

61. Thunström M. Severe sleep problems in infancy associated with subsequent development of attention-deficit/hyperactivity disorder at 5.5 years of age. Acta Paediatr. 2002;91(5):584-592.

62. Gottlieb DJ, Vezina RM, Chase C, et al. Symptoms of sleep-disordered breathing in 5-year-old children are associated with sleepiness and problem behaviors. Pediatrics. 2003;112(4):870-877.
63. Owens JA, Mehlenbeck R, Lee J, King MM. Effect of weight, sleep duration, and comorbid sleep disorders on behavioral outcomes in children with sleep-disordered breathing. Arch Pediatr Adolesc Med. 2008;162(4):313-321.

64. Kass SJ, Wallace JC, Vodanovich SJ. Boredom proneness and sleep disorders as predictors of adult attention deficit scores. J Atten Disord. 2003;7(2):83-91

65. Achenbach TM. Integrative guide for the $1991 \mathrm{CBCL} / 4-18, \mathrm{YSR}$, and TRF profiles. Department of Psychiatry, University of Vermont, Burlington, VT; 1991

66. Thorpy MJ, Rochester M. International Classification of Sleep Disorders: Diagnostic and Coding Manual. Diagnostic Classification Steering Committee-American Sleep Disorders Association; 1991.

67. Conners C, Barkley R. Rating scales and checklists for child psychopharmacology. Psychopharmacol Bull. 1985;21(4):809-843.

68. Conners CK, Sitarenios G, Parker JDA, Epstein JN. The revised Conners' Parent Rating Scale (CPRS-R): factor structure, reliability, and criterion validity. J Abnorm Child Psychol. 1998;26(4):257-268.

69. Bruni O, Ottaviano S, Guidetti V, et al. The Sleep Disturbance Scale for Children (SDSC). Construction and validation of an instrument to evaluate sleep disturbances in childhood and adolescence. J Sleep Res. 1996;5(4):251-261.

70. DuPaul GJ, Power TJ, Anastopoulos AD, Reid R. ADHD Rating Scale-IV: Checklists, Norms, and Clinical Interpretation. New York, NY: Guilford Press; 1998.

71. Conners CK. Conners'Rating Scales - Revised: User's Manual: Toronto, ON: Multi-Health Systems; 1997.

72. Allen RP, Picchietti D, Hening WA, Trenkwalder C, Walters AS, Montplaisi J. Restless legs syndrome: diagnostic criteria, special considerations, and epidemiology: A report from the restless legs syndrome diagnosis and epidemiology workshop at the National Institutes of Health. Sleep Med. 2003;4(2):101-119.

73. Johns MW. A new method for measuring daytime sleepiness: the Epworth sleepiness scale. Sleep. 1991;14(6):540-545.

74. Soldatos CR, Dikeos DG, Paparrigopoulos TJ. Athens Insomnia Scale: validation of an instrument based on ICD-10 criteria. J Psychosom Res. 2000;48(6):555-560.

75. Achenbach TM. Manual for the Young Adult Self-Report and Young Adult Behavior Checklist. Department of Psychiatry, University of Vermont, Burlington, VT; 1997.
Nature and Science of Sleep

\section{Publish your work in this journal}

Nature and Science of Sleep is an international, peer-reviewed, open access journal covering all aspects of sleep science and sleep medicine, including the neurophysiology and functions of sleep, the genetics of sleep, sleep and society, biological rhythms, dreaming, sleep disorders and therapy, and strategies to optimize healthy sleep. The journal welcomes

\section{Dovepress}

original research, clinical \& epidemiological studies, reviews \& evaluations, case reports and extended reports. The manuscript management system is completely online and includes a very quick and fair peerreview system, which is all easy to use. Visit http://www.dovepress.com/ testimonials.php to read real quotes from published authors. 